\title{
Assessing Individuals Learning's Impairments from a Social Entropic Perspective
}

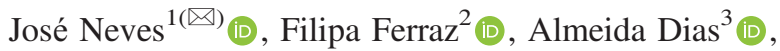 \\ António Capita $^{3,4}$ (D), Liliana Ávidos ${ }^{3}$ (D), Nuno Maia ${ }^{2}$ (D), \\ Joana Machado $^{5}$ (D), Victor Alves ${ }^{1}$ (D) , Jorge Ribeiro ${ }^{6}$ (D), \\ and Henrique Vicente ${ }^{1,7}$ (D) \\ ${ }^{1}$ Centro Algoritmi, Universidade do Minho, Braga, Portugal \\ \{jneves,valves\}@di.uminho.pt \\ 2 Departamento de Informática, Escola de Engenharia, Universidade do Minho, \\ Braga, Portugal \\ filipatferraz@gmail.com, nuno.maia@mundiservicos.pt \\ ${ }^{3}$ CESPU, Instituto Universitário de Ciências da Saúde, Gandra, Portugal \\ a.almeida.dias@gmail.com, \\ antoniojorgecapita@gmail.com, \\ liliana.avidos@ipsn.cespu.pt \\ 4 Instituto Superior Técnico Militar, Luanda, Angola \\ ${ }^{5}$ Farmácia de Lamaçães, Braga, Portugal \\ joana.mmachado@gmail.com \\ ${ }^{6}$ Escola Superior de Tecnologia e Gestão, ARC4DigiT - Applied Research \\ Center for Digital Transformation, Instituto Politécnico de Viana do Castelo, \\ Viana do Castelo, Portugal \\ jribeiro@estg.ipvc.pt \\ ${ }^{7}$ Departamento de Química, Escola de Ciências e Tecnologia, \\ Centro de Química de Évora, Universidade de Évora, Évora, Portugal \\ hvicente@uevora.pt
}

\begin{abstract}
Individuals with Learning Impairments ( $L I)$ may have not only language problems as reading, spelling and writing, but also difficulties in terms of their relationship with the society, i.e., may have glitches not only with language but also with social handiness. On the other hand, the dimension that most contributes to the process of acceptance or integration of an individual in a learning environment or in the society in general, is Emotional Intelligence, i.e., emotion is the foundation for creativity, passion, optimism, drive, and transformation. Motivation is a synonym for enthusiasm, initiative, and persistence. The technical skills have passed to the bottom, since they denote the rational that sustains an individual's involvement in such processes. Indeed, among other things, this is the reason why this work focuses on $L I$ and its various manifestations and how it may affect, evaluate and treat the natural development of a human being and the environment (society) in which him/her is immersed.
\end{abstract}

Keywords: Learning Impairment • Emotional Intelligence •

Learning Impairment Entropic based Social Machine - Logic Programming • Knowledge Representation and Argumentation · Artificial Neural Networks 